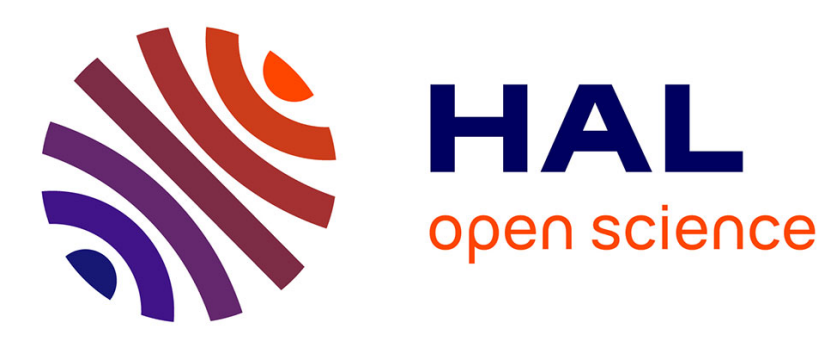

\title{
Highly Compact Composite Antenna
}

Mélusine Pigeon, Christophe Morlaas, Hervé Aubert, Bernard Souny

\section{To cite this version:}

Mélusine Pigeon, Christophe Morlaas, Hervé Aubert, Bernard Souny. Highly Compact Composite Antenna. APS/URSI 2009, Antennas and Propagation Society International Symposium, Jun 2009, Charleston, United States. pp 1-5, 10.1109/APS.2009.5171746 . hal-01022227

\section{HAL Id: hal-01022227 https://hal-enac.archives-ouvertes.fr/hal-01022227}

Submitted on 23 Sep 2014

HAL is a multi-disciplinary open access archive for the deposit and dissemination of scientific research documents, whether they are published or not. The documents may come from teaching and research institutions in France or abroad, or from public or private research centers.
L'archive ouverte pluridisciplinaire HAL, est destinée au dépôt et à la diffusion de documents scientifiques de niveau recherche, publiés ou non, émanant des établissements d'enseignement et de recherche français ou étrangers, des laboratoires publics ou privés. 


\title{
Highly Compact Composite Antenna
}

\author{
M. Pigeon ${ }^{(1,2)}$, C. Morlaas ${ }^{(1)}$, H. Aubert ${ }^{(2,3)}$ and B. Souny ${ }^{(1)}$ \\ (1) LETA/ENAC, 7 avenue Edouard Belin, 31055 Toulouse cedex 4, France \\ (2) Toulouse University; UPS, INSA, INP, ISAE; LAAS; 31077 Toulouse, France \\ (3) CNRS ; LAAS ; 7 avenue du colonel Roche, 31077 Toulouse, France \\ E-mail: melusine.pigeon@recherche.enac.fr
}

\section{Introduction}

These last four decades have seen a race to miniaturize the Radio-Frequency part of popular devices. The antenna has to present not only very high compactness but also a very good integration with the surrounding devices. Decreasing the antenna size concentrates the electromagnetic fields in the radiating structure formed by the antenna. So the associated quality factor increases a lot and the bandwidth decreases. Moreover the antenna losses increase and so the efficiency decreases. A trade-off has to be found between the size, the bandwidth and the efficiency of the antenna (see, e.g., [2]). An original solution combining high compactness and excellent integration capabilities is proposed in this communication. It consists of the particular combination of two equivalent magnetic and electric current distributions. Contrarily to the classical small ceramic microstrip antenna [1], this composite solution can be advantageously used at low frequency regimes.

\section{The magnetic/electric dipoles composite antenna}

The proposed antenna is shown in Fig. 1. The flattened helical part is equivalent to an inductance placed above a metallic plane $(1,5 \mathrm{~mm}$ above). Capacitances are distributed between the helical part and the metallic plane. Such radiating element is equivalent to an electric loop loaded with a capacitance. It consists of a shorted half-wavelength helical line and its modes are those of the half wavelength antenna. The helical part can be replaced by equivalent magnetic current source $\mathbf{M}$ as shown in Fig.1. The version of the helical part to one loop only is equivalent to the Wheeler loop [3]. However the distributed capacitance between the helical part and the metallic plane facilitates in the present antenna the fabrication by using the classical printed circuit technology. In the region where the electric field takes high values (i.e., in the shores of the helical part) the excitation of the helical part is achieved by electrical coupling. The excitation consists of a microstrip line (see Fig. 2). The length, the width and the proximity of this excitation line from the helical part achieve $50 \Omega$ impedance matching. The excitation can also be performed by using the magnetic coupling via the loop located at the center of the helix but we have observed that a good coupling is difficult to reach in practice. The second part of the antenna is the metallic plane placed below the helical part. This metallic plane supports equivalent electric current density distribution generated by the abovementioned magnetic current distribution (see. Fig. 3). Consequently the electromagnetic field radiated by the antenna consists of the combination of the fields radiated by the above-mentioned equivalent electric and magnetic current distributions. The antenna radiates a linear polarized field. Constructive interferences can be achieved above the metallic plane while destructive interferences can be generated below this plane. The

dimensions and the distance to the helical part of the metallic plane control the radiation pattern and the efficiency of the composite antenna. Since the electromagnetic field is 
highly concentrated around the helical part of the antenna, the performances of the proposed radiating element are not sensitive to the surrounding (e.g., components or circuitry located on the metallic plane).

\section{Design and realization of the composite antenna}

The chosen operating frequency is $1.575 \mathrm{GHz}$. The center part length, width and height are denoted by respectively $\mathrm{L}, \mathrm{W}$ and $\mathrm{H}$. The number of loops, the width of the printed microstrip lines and the distance between the lines are denoted respectively by $\mathrm{N}$, a and $\mathrm{d}$. From the dispersion diagram of the helical line corresponding to given $\mathrm{W}, \mathrm{H}$, a and $\mathrm{d}$ of an elementary cell we can derive L. The phase velocity V' of the elementary cell and the phase velocity $\mathrm{V}$ of the same size cell in free-space are derived from this diagram. Next, from the equation $\mathrm{V} / \mathrm{V}^{\prime}=\lambda / \lambda^{\prime}$, where $\lambda$ denotes the free-space wavelength, we determine the wavelength $\lambda^{\prime}$ from which the length $L$ is derived $\left(L=\lambda^{\prime} / 2\right)$. Finally we deduce the antenna characteristic parameter: $\mathrm{L}=15 \mathrm{~mm}, \mathrm{~W}=15 \mathrm{~mm}, \mathrm{H}=3,05 \mathrm{~mm}, \mathrm{~N}=2, \mathrm{a}=2,5 \mathrm{~mm}$ and $\mathrm{d}=3,5 \mathrm{~mm}$. This theoretical length $\mathrm{L}$ has to be reduced in order to compensate the edge effects. The finite-sized metallic plane $\left(50 \times 50 \times 1.57 \mathrm{~mm}^{3}\right)$ is obtained from the metallization of a glass-Teflon substrate $\left(\varepsilon_{\mathrm{r}}=2.55\right)$. The resulting antenna is shown in Fig. 1.

\section{Electromagnetic simulation and measurement of the radiation characteristics of the composite antenna}

The HFSS electromagnetic simulations (including losses) allow us to predict the bandwidth and the efficiency of the antenna around its operating frequency. The simulated bandwidth is $6.5 \mathrm{MHz}$. As shown in Fig. 4, measured results are in good agreement (bandwidth $=8 \mathrm{MHz}$ ) compared to simulated one. Moreover the directivity pattern of the composite antenna is analogous to one of the (simulated) microstrip antenna $(18 \times 18 \times 4 \mathrm{~mm}$ upside a $50 \times 50 \mathrm{~mm}$ metallic plane) operating at the same frequency for a $\theta$ cut in a z0y plane (see coordinate system Fig. 2) as shown in Fig. 5. Note that the maximum directivity is about $4.2 \mathrm{dBi}$. The simulated efficiency $(87 \%)$ of the microstrip antenna is found to be higher than one of the composite antenna (50\%). In Fig. 6, we compare in the $\mathrm{z} 0 \mathrm{y}$ plane the normalized radiation patterns. Note that the results of simulation and measure match correctly. However, contrarily to the classical small ceramic microstrip antenna [1], this composite solution can be advantageously used at low frequency regimes.

\section{Conclusion}

The highly compact antenna proposed in this communication consists of a judicious association of equivalent magnetic current source with equivalent electric current source. This composite antenna presents a directivity radiation pattern analogous to one of the microstrip ceramic antennas but can be used at low frequencies. The antenna measurements confirm the promising performances obtained from electromagnetic simulations.

\section{References}

[1] L. Yeh-Chian ,C. Tsung-Wen,W. Kin-Lu, « Small-size surface-mountable circularly polarized ceramic-chip Antenna for GPS Application ", Microwave and optical Technology letters, Vol 40, Issue 4, pp 300-302, January 2004 
[2] J.S. McLean, "A Re-examination of the Fundamental Limits on the Radiation $Q$ of Electrically Small Antennas ", IEEE Transactions on Antennas and Propagation, Vol.44, NO. 5, May 1996.

[3] H.A. Wheeler, « Small Antennas », IEEE Transactions on Antennas and Propagation, Vol.AP-23, NO.4, July 1975.

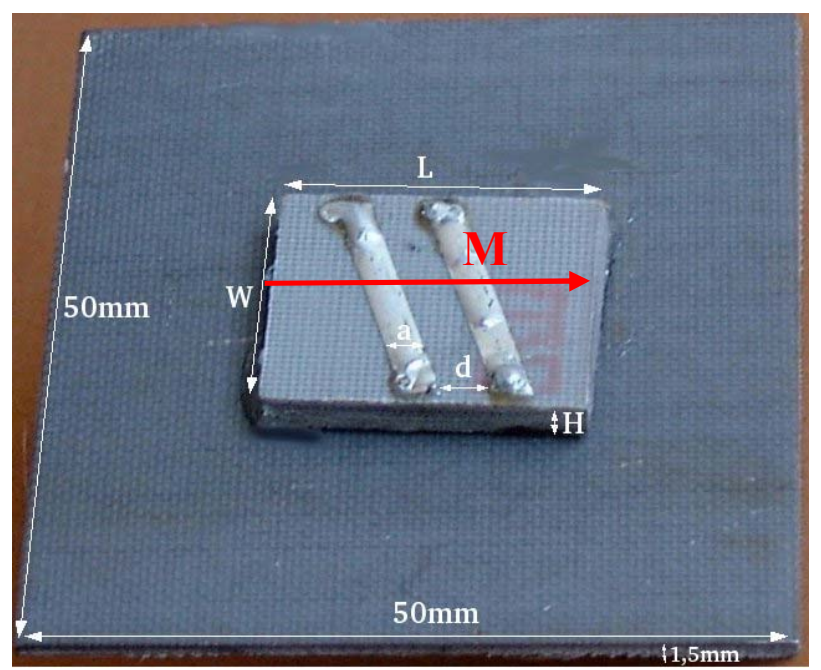

Figure 1: The composite antenna

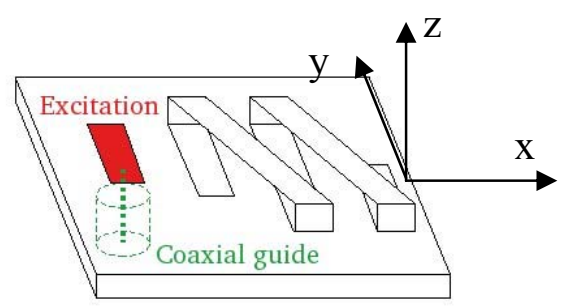

Figure 2: The excitation principle of the helical part with the reference coordinate system.

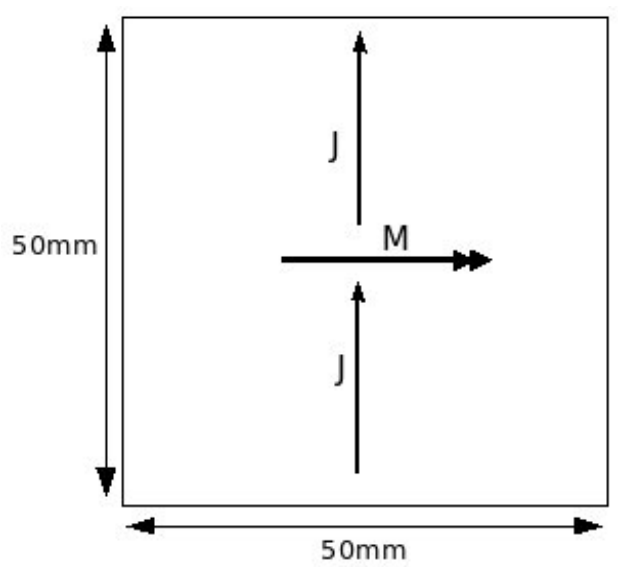

Figure 3: Equivalent electric current distribution 


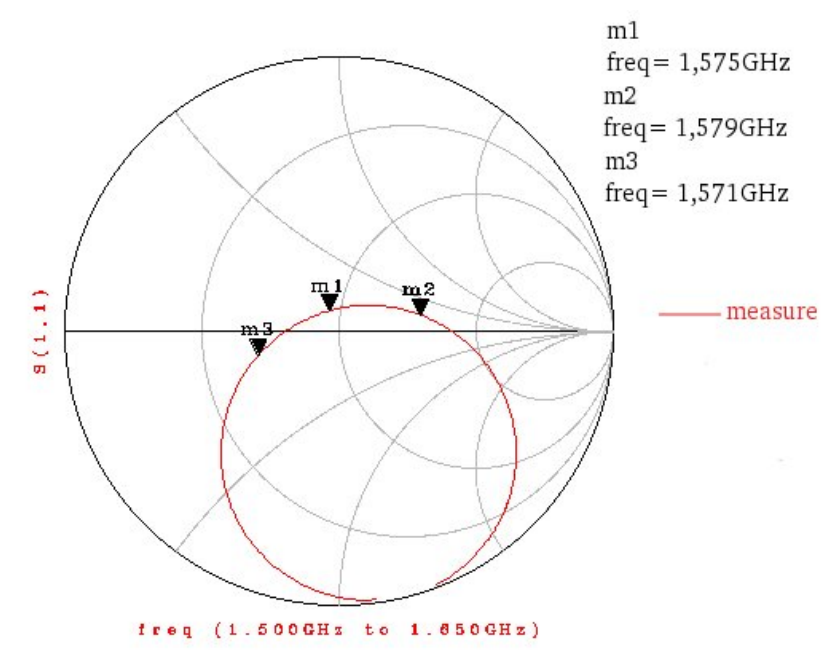

Figure 4: Measured adaptation and bandwidth of the composite antenna

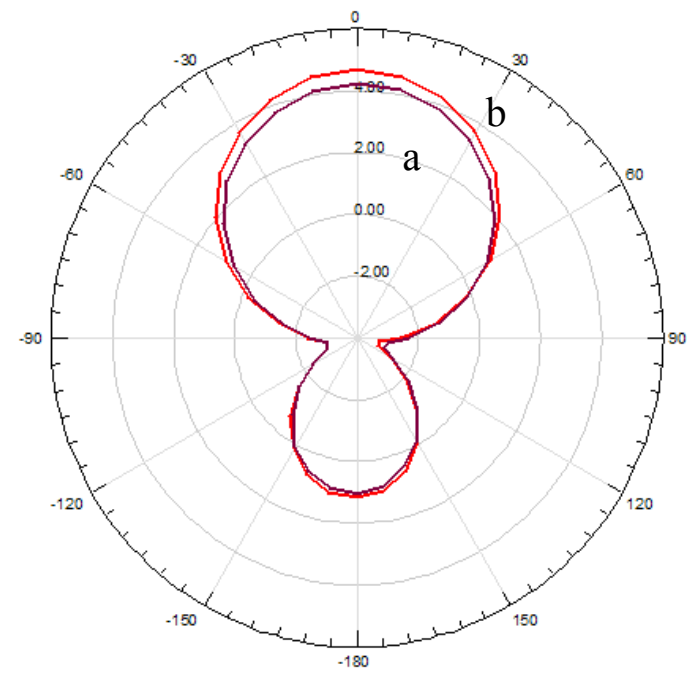

Figure 5: Directivity (dBi) on $\theta$ cut along z0y plane of the (a) composite antenna, (b) microstrip antenna.

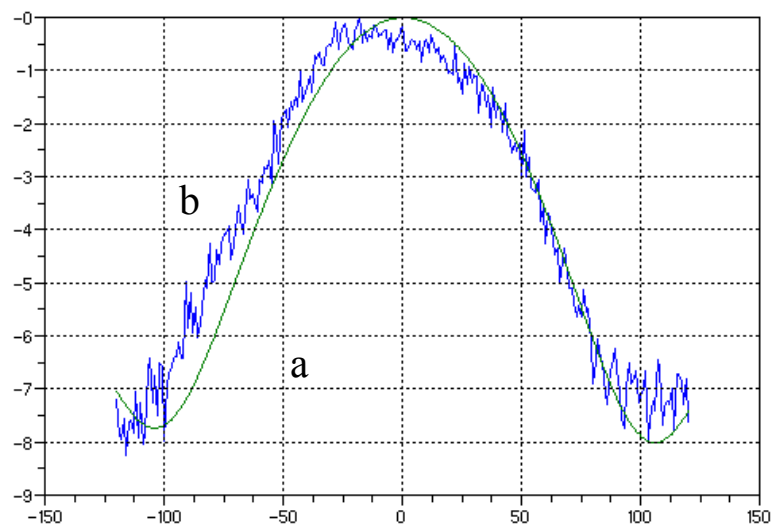

Figure 6: Radiation pattern (dBi) of the composite antenna (a) simulated, (b) measured. 